\title{
Investigation of Addition Titanium Dioxide on General Properties of Polycarbonate
}

\author{
Najim A. Saad, Esraa Rzaq Jwad \\ Polymer and Petrochemical Industries Department, College of Materials Engineering, Babylon University, Babylon, Iraq \\ Email: jasim_910@yahoo.com, esrarazaq1993@gmail.com
}

How to cite this paper: Saad, N.A. and Jwad, E.R. (2018) Investigation of Addition Titanium Dioxide on General Properties of Polycarbonate. Open Access Library Journal, 5: e4229.

https://doi.org/10.4236/oalib.1104229

Received: December 3, 2017

Accepted: January 12, 2018

Published: January 15, 2018

Copyright $\odot 2018$ by authors and Open Access Library Inc.

This work is licensed under the Creative Commons Attribution International License (CC BY 4.0).

http://creativecommons.org/licenses/by/4.0/

\section{(c) (i) Open Access}

\begin{abstract}
Polycarbonate is a transparent commercial engineering polymer used in many applications especially in mobile protector screen for its good properties. In the present paper, nano composite material composed of polycarbonate sheet and nano titanium dioxide particles was prepared. Three ratios of $\mathrm{TiO}_{2}$ (0.01-0.03-0.05 g) were employed with polycarbonate by using pressing technique. Different mechanical, chemical, thermal and morphology tests were characterized as hardness, impact, FTIR, UV,XRD, DSC, tensile strength, contact angle and smoothness test. The results were shown that the hardness decreased in about $15 \%$ and the impact resistance increased in about $10 \%$ with $\mathrm{TiO}_{2}$ level increasing. FTIR showed there were no new peaks appearing and that indicated physical interactions between the nano filler and the polycarbonate matrix, also transparency reduced in about $5 \%$. UV showed the absorption of polycarbonate to radiation after added $\mathrm{TiO}_{2}$. DSC showed decreasing in the $\mathrm{Tg}$ level and increasing in the crystallinity of material after processing. Contact angle test showed that the wettability increased at first but retained decreasing with adding more $\mathrm{TiO}_{2}$ to the surface. Surface roughness test and AFM test show decrease in smoothness with adding $\mathrm{TiO}_{2}$ to polycarbonate sheet.
\end{abstract}

\section{Subject Areas \\ Mechanical Engineering}

\section{Keywords}

Nanocomposite, Titanium Dioxide Particles, Polycarbonate, Physical, Chemical and Morphology Properties

\section{Introduction}

Polycarbonate is a transparent commercial engineering polymer used in many applications due to its properties such as high shock resistance, thermal stability, 
toughness and good optical properties as well as other mechanical properties [1]. According to the physical and mechanical properties of polycarbonate making it important in many industries, it replaces the glasses in different applications as display panels of electrical tools, low weight eyewear lenses and compact disks, but metal is better than polycarbonate in electrical and thermal properties [2].

Polycarbonates are mainly used in electrical insulators also used in production of Blu-ray Discs and DVDs [3]. Polycarbonate is showing incompatibility with acetone and ammonia which can dissolve it, but alcohol used to clean the surface of polycarbonate sheet after used [4]. Polycarbonate is improved by using nanoparticles to obtain polycarbonate nanocomposite with new physical, electrical and mechanical properties. Thin transparent layers contain $\mathrm{TiO}_{2}$ studied and the interest in them has increased in recent years intensively because of application potential including Photocatalytic and Water Air Purification [5]. The surface antifogging and easily washable result from super-hydrophilic property of the surface allow the water to spread through the surface. Titanium dioxide is the most nanoparticles that used in many applications involving photocatalytic, optoelectronic activities and electrochromic application [6].

$\mathrm{TiO}_{2}$ is considered as one of the important environmentally friendly materials to be used to create new applications for renewable energy [7]. Thin film of $\mathrm{TiO}_{2}$ describes as antifogging effect, self-cleaning and it's widely used in glass industry. Super hydrophilicity of the of $\mathrm{TiO}_{2}$ thin film obtains the antifogging effect to the surface. Polycarbonate- $\mathrm{TiO}_{2}$ nanocomposite could be prepared by different coating methods such as spray ion beam evaporation, plasma enhanced, spin coating, dipping, chemical vapor deposition and pressing method [8].

The introduction of nanoparticle had been widely investigated and reported to be the most efficient method to improve the properties of polycarbonate. The self-cleaning coating has been used in new applications including buildings, sculptures, cars and machinery. This coating is based on $\mathrm{TiO}_{2}$ optical stimulation. $\mathrm{TiO}_{2}$ self-cleaning with polycarbonate material shows better scratch resistance and hardness. Perfect mechanical properties of self-cleaning coating make them useful in many applications [9].

Houman et al. [10] prepared self-cleaning coating from $\mathrm{TiO}_{2}$ on polycarbonate surface by using dip coating process and treating the surface with chemical solution to obtain hydrophilic groups on surface in ultrasonic device and washing then with DI. The results showed improvement in mechanical properties after coating included increases in hardness in about 2.5 time and scratch resistance increases in about 6.4 time then PC substrates. The transparency of PC- $\mathrm{TiO}_{2}$ decreased in about $10 \%-15 \%$.

Nima et al. [11] improve the properties of polycarbonate by prepared films of polycarbonate- $\mathrm{TiO}_{2}$ nano composite. The film formed by using Solvent evaporation method and studied the mechanical properties of nanocomposite films by conducting tensile tests and hardness measurement. The result from tensile test showed that stress-strain peak had increased with increased $\mathrm{TiO}_{2}$ nano particles content and elastic modulus increased with $\mathrm{TiO}_{2}$ nanoparticle weight fraction. 
Al-Shammary, Z. R. [12] prepared $\mathrm{PC}-\mathrm{TiO}_{2}$ and $\mathrm{PS}-\mathrm{TiO}_{2}$ composites at room temperature and studied the effect of $\mathrm{TiO}_{2}$ on tensile properties. The results showed reducing in ultimate stress and young modulus compared to PC and PS pure. Also, the toughness became stabilized because $\mathrm{TiO}_{2}$ particle made these chains interlocked and mobility of chains became restrict.

The aim of this paper is to improve the surface properties of polycarbonate by addition $\mathrm{TiO}_{2}$ nanoparticles. The pressing technique used to insert nanoparticles on the surface. This sample latter if needed excellent properties and homogenous in structure, they reformed by cutting them and extrude through twin-screw extruder device.

\section{Experimental Part}

\subsection{Materials}

The used materials in this research are polycarbonate (PC) and titanium dioxide nano particles $\left(\mathrm{TiO}_{2}\right)$. The used polycarbonate sheet is as Table 1 and $\mathrm{TiO}_{2}$ nanoparticles as Table 2 by used pressing method with temperatures and pressure as Table 3.

Table 1. Mechanical and physical properties of PC.

\begin{tabular}{ccc}
\hline Property & Units & Value \\
\hline Tensile Strength & $(\mathrm{Mpa})$ & 37.5 \\
Tensile Modulus of Elasticity & $(\mathrm{KN})$ & 0.3 \\
Melting Point & $\left({ }^{\circ} \mathrm{C}\right)$ & 269 \\
Processes Temperature & $\left({ }^{\circ} \mathrm{C}\right)$ & $180-200$ \\
Impact Strength & $\left(\mathrm{J} / \mathrm{mm}^{2}\right)$ & 45 \\
Density & $\left(\mathrm{g} / \mathrm{cm}^{3}\right)$ & 1.902 \\
Hardness & $($ Shore D) & 81.1 \\
\hline
\end{tabular}

Table 2. The specification of titanium dioxide nanoparticles.

\begin{tabular}{cc}
\hline Product name & $\mathrm{TiO}_{2}$ powder nanograde \\
\hline Color & White \\
Particle size & $45 \mathrm{~nm}$ \\
$\mathrm{TiO}_{2}$ content & $\geq 99.8 \%$
\end{tabular}

Table 3. Pressing information.

\begin{tabular}{cc}
\hline Polycarbonate & 3 samples $(5 \mathrm{~cm} \times 5 \mathrm{~cm} \times 2 \mathrm{~mm})$ \\
\hline $\mathrm{TiO}_{2}$ powder & $1 \%-3 \%-5 \%$ \\
Temperature & $190^{\circ} \mathrm{C}-200^{\circ} \mathrm{C}$ \\
Temperature & $2 \mathrm{Map}$ \\
Time & $5 \mathrm{~min}$ \\
\hline
\end{tabular}




\subsection{Samples Preparation}

At first cleaning the surface of polycarbonate sheets $(5 \mathrm{~cm} \times 5 \mathrm{~cm})$ with thickness of $2 \mathrm{~mm}$ with ethanol and washed with Distilled water then dried in electrical oven for 2 hours. After cleaning, dispersed $\mathrm{TiO}_{2}$ powder on the surface. Cover $\mathrm{PC}-\mathrm{TiO}_{2}$ with a piece of sulfone to prevent the adhesion of the powder with the piston plates and for the interference of the nanoparticles to the cavities that cannot see in the surface. The large particle remain on the surface, therefore after pressing washed the sheet again with ethanol and Distilled water then dried.

Tests: Mechanical tests have been conducted (hardness, surface roughness and impact test) Includes standard specifications: for impact test-ASTMD256-87 by used charpy type instrument. Hardness of polycarbonate prepared according to ASTM D 2240. Tensile strength for PC with addition was performed by using (Bongshin model WDW-SE) instrument according to ASTM D-638-IV. Also used microstructure test as contact angle test used device was SL 200C-Optical Dynamic I Static Interfacial Tensiometer \& Contact Angle Meter which manufactured in KINO Industry Co., Ltd., USA with contact angle range from 0 o to 180 o. FTIR-test also used to characterize the structure performed by using (FT-IR-OPUS_7.0 manufacturing by Bruker Company). UV-Vis double beam spectrophotometers, (SHIMADZU, UV-1800, Japan) used to check the absorbance of nanocomposite for different energy. DSC test was performed according to ASTM D3418-03 manufacturing by japan. AFM-Test was carried by tapping mode SPM model AA3000 ANGSTROM ADVANCED INC., USA, 2008 (AFMContact Mode). This test was performed using XRD 6000 instrument, manufactured by (SHIMADZU)-Japan.

\section{Results and Discussion}

\subsection{Mechanical Test}

\subsubsection{Hardness Test}

The hardness for pure and nanocomposite material measure are by using shore hardness (D). The result of this test appear decreased in the hardness compared to pure that indicate to increase the flexibility with decreased the rigidity of material after addition of $\mathrm{TiO}_{2}$ as Figure 1 .

\subsubsection{Toughness}

Showed from this test impact strength of material and it consider one of the ways to known the flexibility of polycarbonate pure and polycarbonate with $\mathrm{TiO}_{2}$. In which the impact improved after addition $3 \%$ of $\mathrm{TiO}_{2}$ make them better when the nanocomposite subjected to shock or loads as in Figure 2.

\subsubsection{Tensile Strength Test}

The Tensile strength of PC nanocomposite decreased with increasing the proportion of $\mathrm{TiO}_{2}$ nanoparticles from 1 to $5 \mathrm{wt} \%$ as shown in Figure 3. The maximum tensile strength was obtained with PC-pure Figure 4, while the nanocomposite 


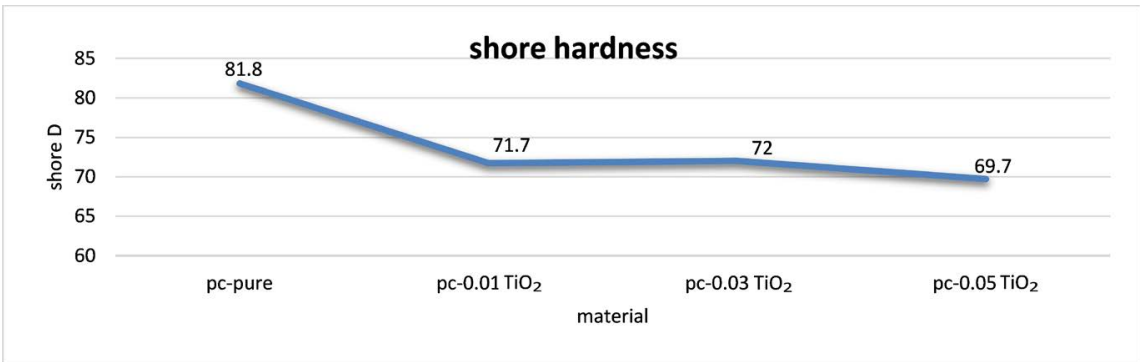

Figure 1. Representing shore hardness (D) test.

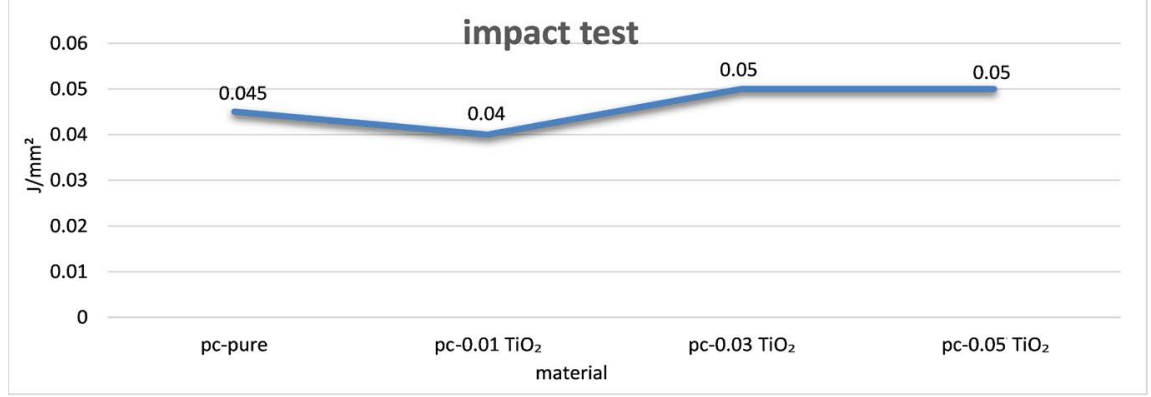

Figure 2. Representing the impact test.

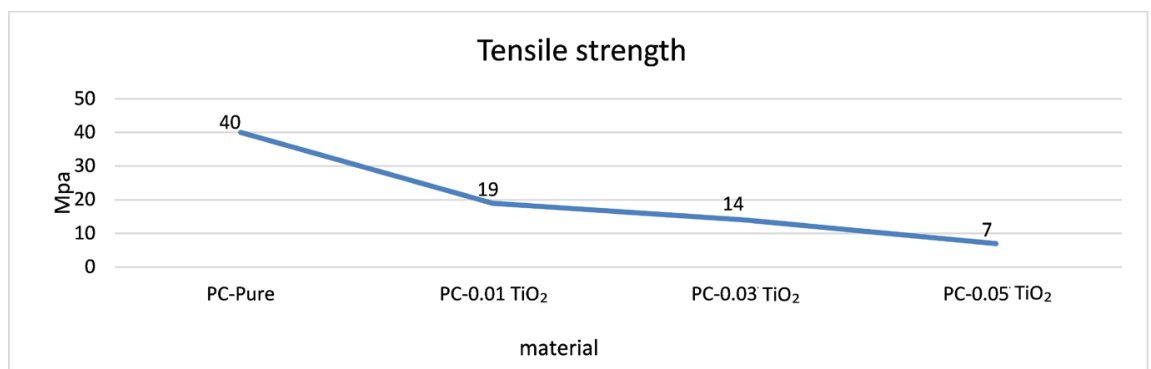

Figure 3. Representing the tensile strength.

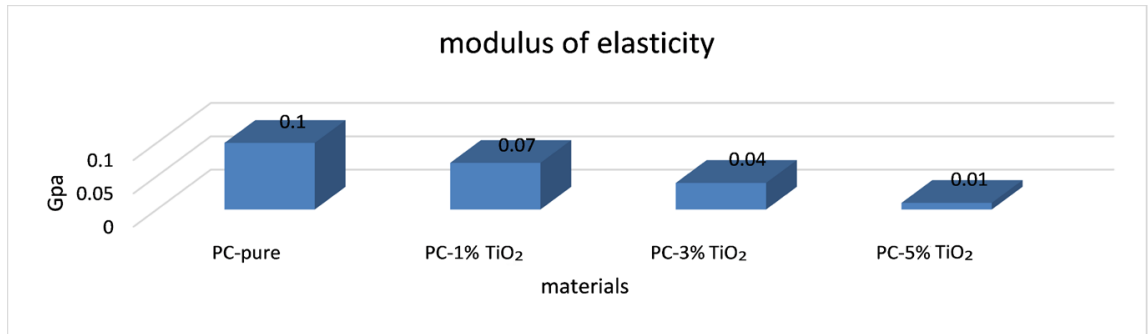

Figure 4. Representing the modulus of elasticity.

with 1, 3 and 5 wt\% occurs decreased in the tensile strength. Also, the modulus of elasticity decreases with addition $\mathrm{TiO}_{2}$ nanoparticles. The results in this work agree with Z. Shammary [12].

\subsection{Microstructure Test}

\subsubsection{Wettability}

The wettability of material measured by using contact angle test in which the 
wettability decreases with addition $\mathrm{TiO}_{2}$ nanoparticles is as in Figure 5. The increases in wettability in a specific range better for self-cleaning properties in the surface to remove the contaminated. In this case the $\mathrm{TiO}_{2}$ works as an automatic cleaning agent in the material. Contact angle changed with surface tension of the liquid, surface topography (surface roughness), level of interaction (between the liquid and solid) and surface energy of the substrate.

\subsubsection{Surface Roughness Test}

From this, the smoothness for polycarbonate-pure and nanocomposite was measured as in Figure 6. The roughness of the surface increased with addition of $\mathrm{TiO}_{2}$ to polycarbonate sheet in pressing technique. The increases of roughness in polycarbonate are due to low-efficiency devices. The roughness also effect on the wettability properties as we said earlier.

\subsubsection{Chemical Structure}

The chemical structure of nanocomposite clarifies by using FTIR-test. The result showed that no new peak appear and that indicate to physical interaction between the polycarbonate structure and $\mathrm{TiO}_{2}$ powder. It is noted from Figure 7 for FTIR curve of PC and PC material with titanium oxide at 1\%, 3\% and 5\%. The peaks PC are observed in the wave numbers $3670 \mathrm{~cm}^{-1}(\mathrm{O}-\mathrm{H})$, at $3498 \mathrm{~cm}^{-1}$ (O-H), at $2715 \mathrm{~cm}^{-1}(\mathrm{C}-\mathrm{H})$ and at $1604 \mathrm{~cm}^{-1}(\mathrm{C}=\mathrm{C})$ after addition $\mathrm{TiO}_{2}$ by $1 \%$, there is an increase in transmittance. The transmittance value of the pure polymer increased very little and the (Ti-O-Ti) showed at $634 \mathrm{~cm}^{-1}$. After increasing the ratio of $\mathrm{TiO}_{2}$ to $3 \%$ and $5 \%$, it is obvious that titanium oxide reduces the amount of radiation due to increased particle size that increases the absorption of the material and its reflection. Moreover, this leads to less permeability.

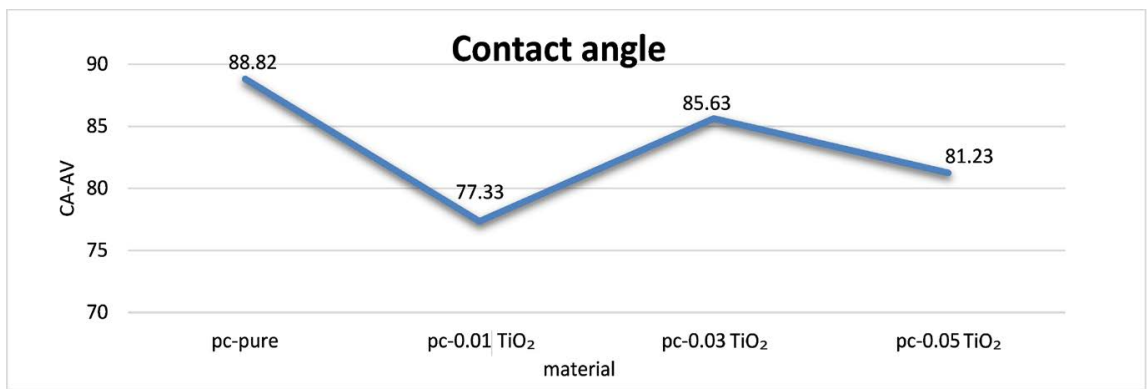

Figure 5. Representing contact angle test at 1 min (According to young Laplace).

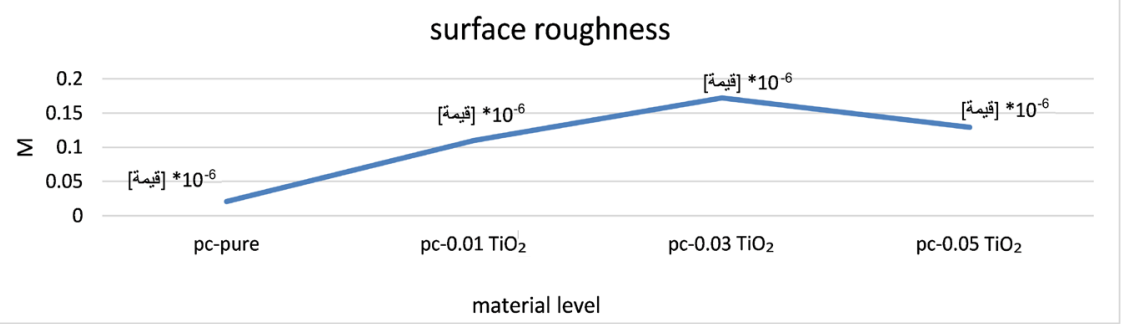

Figure 6. Representing the surface roughness test. 


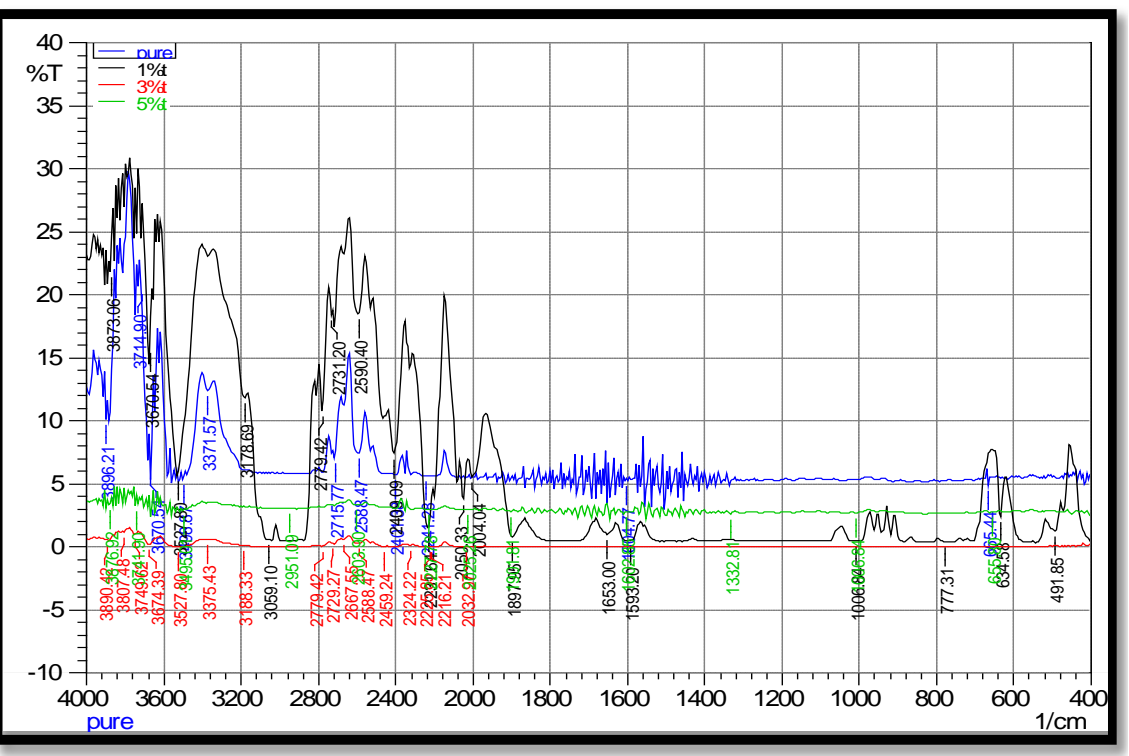

Figure 7. FTIR for PC-pure, PC with (1\%, $3 \%$ and 5\%) $\mathrm{TiO}_{2}$.

\subsubsection{UV-Test}

The use of $\mathrm{TiO}_{2}$ is to avoid the photo-degradation of polycarbonate because $\mathrm{TiO}_{2}$ have ability to absorb ultraviolet radiation as shows in Figure 8. Uv-vis give the amount of absorption when added $\mathrm{TiO}_{2}$. It is also noticed from Figure that there are a slight decrease in absorption as the percentage of addition increase and formation of a more cohesive membrane due to filling the blanks. Also noted through the form, the randomness or confusion in the curve decreases as the proportion of titanium dioxide increases. While, at 5\% of titanium, there is a clear decrease in the absorption curve in area of UV. This happen due to addition of high ratio of titanium to the polymer material obtained transparent so that the ultraviolet light passes through them. This considered an undesirable proportion because the ultraviolet rays harmful to the human eye. Therefore, the best rate is less than this ratio $\left(5 \% \mathrm{TiO}_{2}\right)$ to prevent the crystallization that occurs in this ratio.

\subsubsection{DSC-Test}

This test shows $\mathrm{Tg}$ and $\mathrm{Tm}$ for polycarbonate before and after addition of $\mathrm{TiO}_{2}$ in different level. $\mathrm{TiO}_{2}$ decreased $\mathrm{Tg}$ with decreased hardness of polycarbonate that mean the flexibility of material increases and this better for the flexible screen as Figure 9. $\mathrm{Tg}$ decreased from $152^{\circ} \mathrm{C}$ for pure to $144^{\circ} \mathrm{C}$ and $143^{\circ} \mathrm{C}$ for nanocomposite.

\subsubsection{Morphology Test}

From this test describe the roughness of the surface after addition $\mathrm{TiO}_{2}$ to the polycarbonate sheet; also know the size of $\mathrm{TiO}_{2}$ particle. With increases the grain size of particle, reduces the light transmission due to increases the crystallinity of nanocomposite as shown in Figure 10. In addition, the distribution of nanoparticle was good on the polycarbonate surface. 


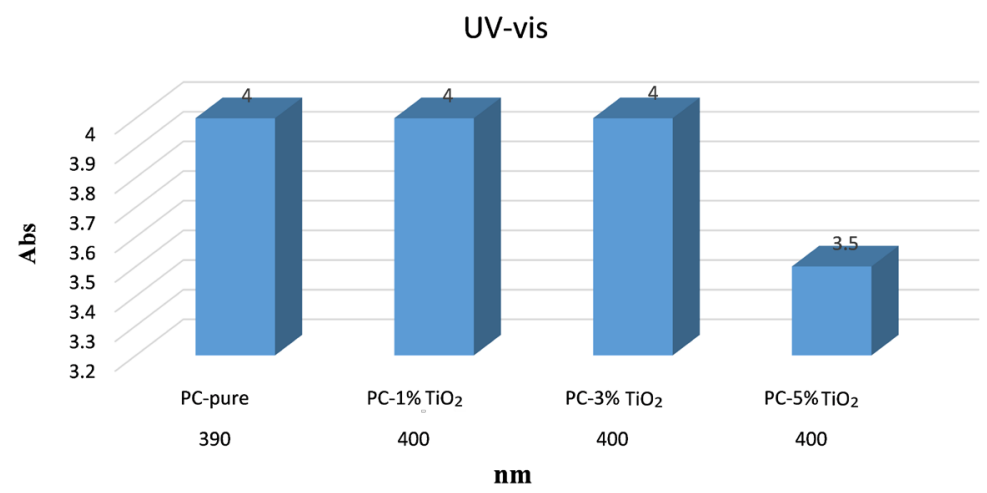

Figure 8. UV-vis for (A) PC-pure; (B) PC-1\% $\mathrm{TiO}_{2}, \mathrm{PC}-3 \% \mathrm{TiO}_{2}$ and $\mathrm{PC}-5 \% \mathrm{TiO}_{2}$.

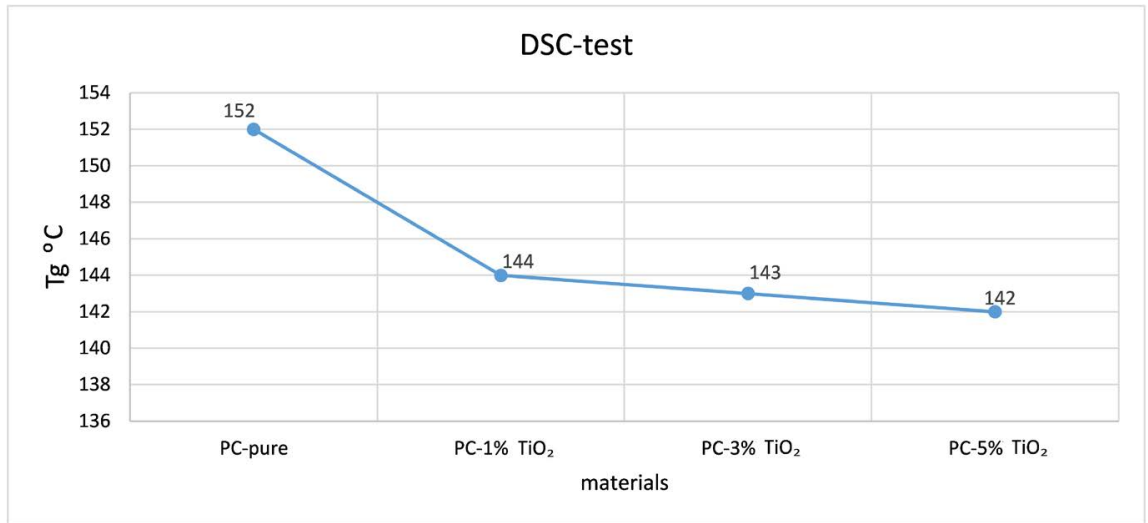

Figure 9. Representing DSC-test (a) PC-pure $152^{\circ} \mathrm{C}$; (b) PC-0.01 $\mathrm{TiO}_{2}$; (c) PC-0.03 $\mathrm{TiO}_{2}$; (d) $\mathrm{PC}-0.05 \mathrm{TiO}_{2}$.

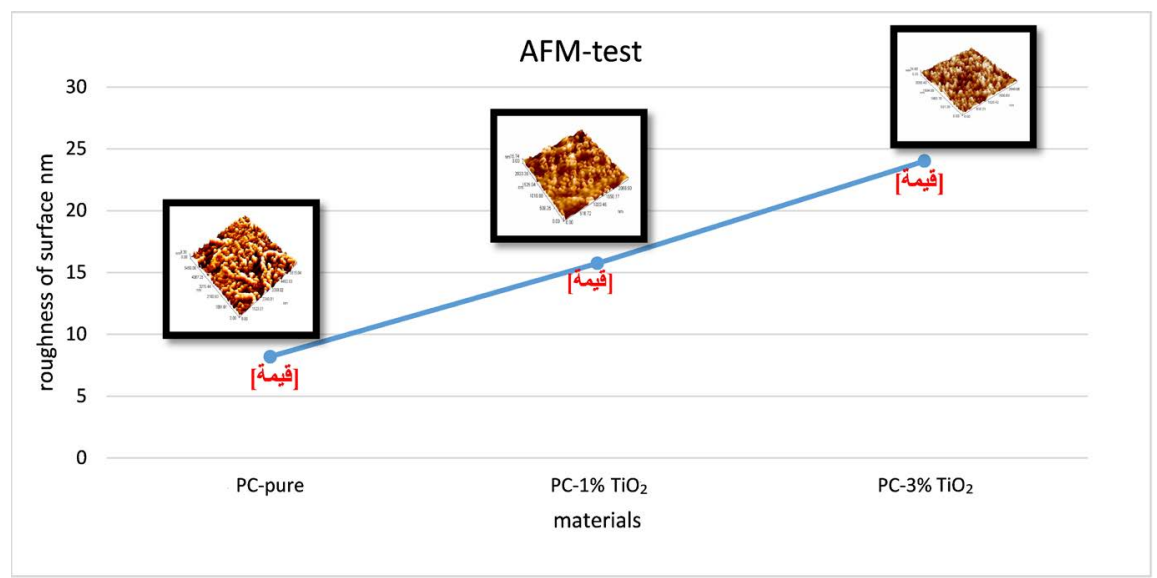

Figure 10. Representing the AFM test for polycarbonate pure and nanocomposite.

\subsubsection{XRD Test}

XRD Patterns of PC and PC with (1, 3 and 5 wt\%) $\mathrm{TiO}_{2}$ shown in Figure 11. PC shows single peak that related to amorphous structure of it. Addition, $\mathrm{TiO}_{2}$ to $\mathrm{PC}$ matrix appears change in the peak of PC matrix as in $2 \theta=25.2^{\circ}$ related to (101) plans of anatase with level $1 \mathrm{wt} \%$ of $\mathrm{TiO}_{2}$ and this agree with Nima et al. [11]. 

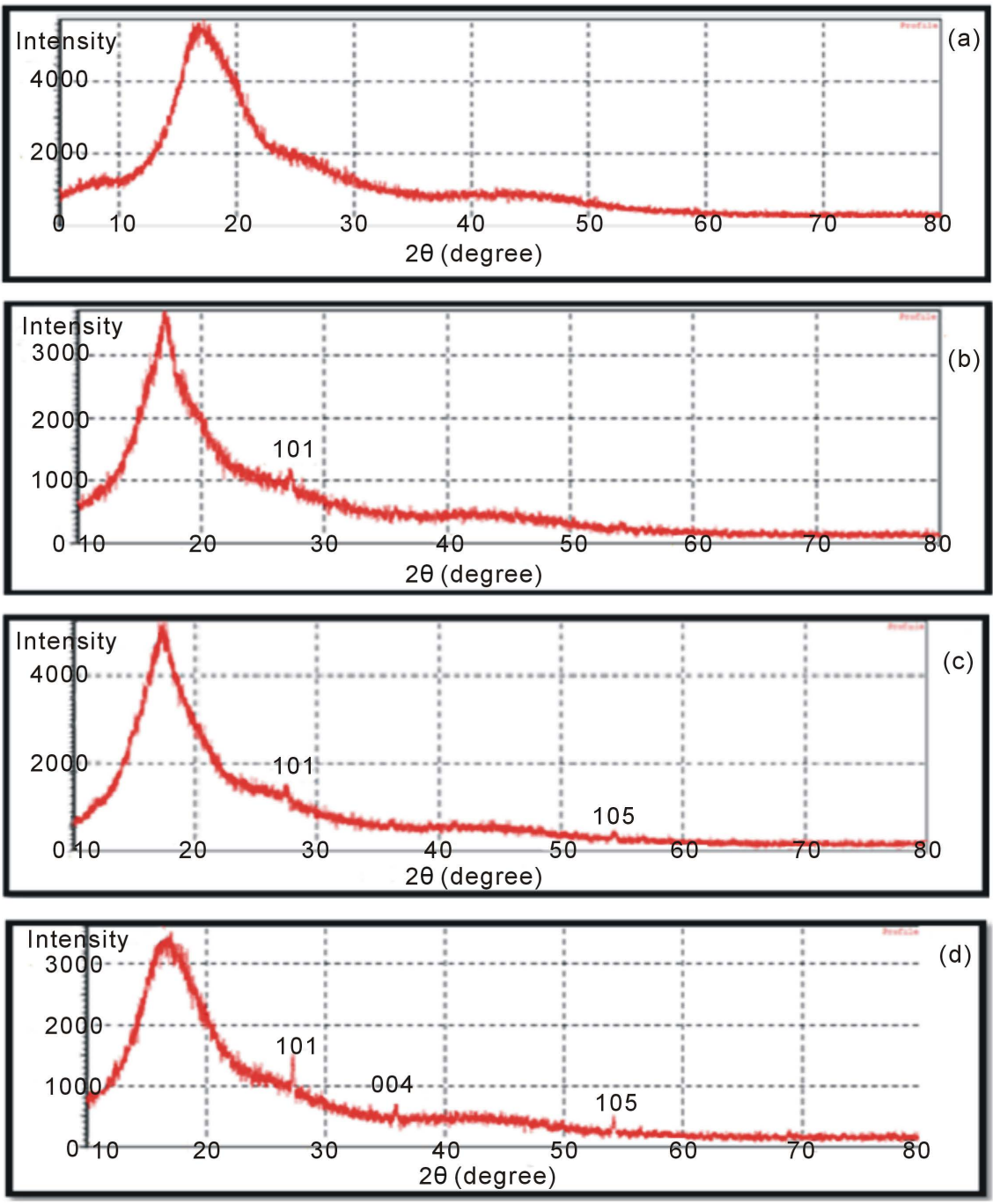

Figure 11. XRD polycarbonate- $\mathrm{TiO}_{2}$ nanocomposite (a) Pure-polycarbonate; (b) PC-0.01 $\mathrm{TiO}_{2}$; (c) PC-0.03 $\mathrm{TiO}_{2}$; (d) PC-0.05 $\mathrm{TiO}_{2}$.

When increasing the amount of $\mathrm{TiO}_{2}$ in $\mathrm{PC}$ matrix causes physical interface as shows in test. The peak from X-ray diffraction showed that amorphous matrix decreased with increasing the intensity of $\mathrm{TiO}_{2}$ peak after addition titanium dioxide.

\section{Conclusion}

We can conclude that better impact resistance, contact angle, hardness from this work in $0.03 \mathrm{TiO}_{2}$ compared to other levels. FTIR for samples showed physical interaction occurred for polycarbonate; $\mathrm{TiO}_{2}$ also showed that all levels of $\mathrm{TiO}_{2}$ gave the same proportions of transparency. Reducing in tensile and elastic modulus indicated to increase the flexibility of composite with reduced $\mathrm{Tg}$ and increased the crystallinity of material after addition of $\mathrm{TiO}_{2}$. The transparency of polycarbonate sheet decreased with addition of $\mathrm{TiO}_{2}$ and this depended on constriction of powder that used. XRD showed no chemical interaction that oc- 
curred between polycarbonate and $\mathrm{TiO}_{2}$ nanoparticles.

\section{Summary}

Studies have shown the resistance of scratching, hardness and other mechanical properties of polycarbonate are improved by using $\mathrm{TiO}_{2}$ nano-particles. The present work aims to improve the mechanical properties and morphology of the surface without effect on the physical properties as transparency of polycarbonate.

\section{References}

[1] Usuki, A., Kawasumi, M., Kojima, Y., Okada, A., Kurauchi, T. and Kamigaito, O. (1993) Swelling Behavior of Montmorillonite Cation Exchanged for $\omega$-Amino Acids by $\in$-Caprolactam. Journal of Materials Research, 8, 1174-1178. https://doi.org/10.1557/JMR.1993.1174

[2] Wu, L.Y.L., Boon, L., Chen, Z. and Zeng, X.T. (2009) Thin Solid Films. Journal of Materials Science Letters, 517, 4850-4856.

[3] Serini, V. (2000) Polycarbonates. In Ullmann's Encyclopedia of Industrial Chemistry, Wiley-VCH, Weinheim. https://doi.org/10.1002/14356007.a21_207

[4] Zhou, R.-J. and Burkhart, T. (2009) Mechanical and Optical Properties of Nanosilica-Filled Polycarbonate Composites. Journal of Thermoplastic Composite Materials, 4, 487-500.

[5] Hoffmann, M.R., Martin, S.T., Choi, W. and Bahnemann, D.W. (1995) Environmental Applications of Photocatalysis Semiconductor. Chemical Reviews, 95, 69-96. https://doi.org/10.1021/cr00033a004

[6] Yu, J., Zhao, X., Yu, J.C., Zhong, G., Han, J. and Zhao, Q. (2001) The Grain Size and Surface Hydroxyl Content of Super-Hydrophilic $\mathrm{TiO}_{2} / \mathrm{SiO}_{2}$ Composite Nanometer Thin Films. Journal of Materials Science Letters, 20, 1745-1748. https://doi.org/10.1023/A:1012458411717

[7] Aghoubi, H. (2013) Self-Cleaning Materials for Plastic and Plastic-Containing Substrates, Self-Cleaning Materials and Surfaces: A Nanotechnology Approach. In: Daoud, W., Ed., Wiley, Chichester, 153-202.

[8] da Silva Sobrinho, A.S., Czeremuszkin, G., Latreche, M. and Wertheimer, M.R. (2000) Defect-Permeation Correlation for Ultrathin Transparent Barrier Coatings on Polymers. Journal of Vacuum Science \& Technology A, 18, 149-157. https://doi.org/10.1116/1.582156

[9] Fujishima, A., Zhang, X. and Tryk, D.A. (2008) $\mathrm{TiO}_{2}$ Photocatalysis and Related Surface Phenomena. Surface Science Reports, 63, 515-582. https://doi.org/10.1016/j.surfrep.2008.10.001

[10] Yaghoubi, H., et al. (2010) Self-Cleaning $\mathrm{TiO}_{2}$ Coating on Polycarbonate: Surface Treatment, Photocatalytic and Nanomechanical Properties. Surface \& Coating Technology, 204, 1562-1568. https://doi.org/10.1016/j.surfcoat.2009.09.085

[11] Shahazi, N., et al. (2016) Mechanical Properties of Polycarbonate-TiO ${ }_{2}$ Nanocomposite Film. Indian Journal of Pure \& Applied Physics, 54, 241-250.

[12] Al-Shammary, Z.R. (2011) The Effect of Titanium Dioxide on the Tensile Properties of Polycarbonate and Polystyrene Polymers. Iraqi Journal of Physics, 7, 63-66. 